\title{
PLANNING OF MAINTENANCE COST FOR BUSINESS- STORAGE FACILITY USING BIM
}

\author{
Zoran Pučko ${ }^{1}$, Dražen Vincek ${ }^{2}$, Andrej Štrukelj ${ }^{3}$ and Nataša Šuman ${ }^{4}$
}

\begin{abstract}
The aim of this paper is to present case study of the use of BIM approach for planning of maintenance cost of a facility in the operation time of a real business-storage facility in Slovenia. The first part outlines general principles of FM and BIM. Next, the features of facility maintenance are described according to the current Slovenian legislation. In addition, several standards used in other countries, as the result of the mutual development of the FM and BIM, are introduced. After that, step-by-step procedures for planning of maintenance cost are exposed, namely from Element list for maintenance, determination of the lifetime, service measures and cost analysis to development of cost plan in tabular form. The presented cost plan is designed in a unique way in which cost analysis is performed by using BIM approach with linked data to 3D BIM model. Moreover, Construction Project Management Software (Vico Office) is applied. For the purpose of appraisal maintenance costs over the entire life of 60 years, cumulative costs are distributed over the years. Thus, the cost plan is made in tabular form in Excel, presenting visual overview of planned maintenance more explicitly.
\end{abstract}

Keywords: facility maintenance, building information modelling, BIM, cost analysis, cost plan.

\section{INTRODUCTION}

The life of facilities goes through many phases. The project starts after the recognition of needs for buildings. Upon initiation of the project the project is developed as drawings and specifications. Afterwards, a facility is built. By the end of construction works, it is turned over to the owner. A finished facility is occupied, maintained, repaired and renewed in its lifecycle. This is the period of facility operation in which the owner is responsible for ensuring of its functioning and durability.

Undoubtedly, operation and maintenance phase is the longest period in the whole building lifecycle, lasting for many years before a general renovation is needed. This is the period of great expenditure; and studies revealed that operations and maintenance make up 11 percent of the whole lifecycle cost (NIBS, 1998).

Therefore, life time of the facility as well as its cost-effective management is highly dependent on regular and timely maintenance services. These functions of building management aim to maintain or even to increase the value of the building and hold responsibility for maintenance functions, comprising the technical management,

\footnotetext{
1 Assistant, Faculty of Civil Engineering, Transportation Engineering and Architecture, University of Maribor, Smetanova ul. 17, Maribor, SI, zoran.pucko@um.si

2 Gebr. Schmölzl GmbH\&Co.KG, Wappachweg 27, 83457 Bayerisch Gmain, Germany, drasvincek@gmail.com

3 Associate Professor, Faculty of Civil Engineering, Transportation Engineering and Architecture, University of Maribor, Smetanova ul.17, Maribor, SI, andrej.strukelj@um.si

4 Assistant Professor, Faculty of Civil Engineering, Transportation Engineering and Architecture, University of Maribor, Smetanova ul. 17, Maribor, SI, natasa.suman@um.si
} 
operation, maintenance, repair, and emergency management (Roper and Payat, 2014). Furthermore, building management is an important part of the integrated Facility Management (FM) that is defined as the integration of processes within an organisation to maintain and develop the agreed services which support and improve the effectiveness of its primary activities (EN15221-1:2006-1). In addition, OmniClass Construction Classification System provides definition for the terms FM, Facility Operation and Management, and Facility Operations (OCCS - ISO 12006-2). Definitions of FM from the various sources are slightly different due to the relatively short period of use, but the newest definitions of FM highlight the importance of IT.

The expansion of increasingly sophisticated facilities result in the fact that more and more owners and facility managers seek opportunities for providing and supporting all phases of facility lifecycle with widely adopted Building information modelling (BIM). $\mathrm{BIM}$ is a new/comprehensive approach to design, construction and maintenance of facility and represents drawing and documentation tool as well as platform for enhanced interdisciplinary collaboration, and the ability to extend information support throughout building lifecycle. (Eastman et al., 2011; Sabol, 2008). The basic concept is the chain connection of all participants who contribute to the integrated information in the whole building lifecycle within single phases (Pučko et al., 2014). BIM approach deals with the various dimensions from 3D to $6 \mathrm{D}$ or to even more (BIM and facilities management, 2016, Ding et al., 2014). The introduction of BIM approach for design phase is expanding rapidly today e.g. 3D, 4D and 5D models. These models are also increasingly used during the construction of buildings. On the other hand, more and more users emphasize the importance of introducing BIM approach for a period of facility operation by recommending 6D BIM (Becerik-Gerber et al., 2012, McArthur, 2015, Nicał, 2016). Actually, clear guidelines and instructions for 6D BIM creation were not detected so far. However, Pärn et al. (2017) give an extended review of published literature on the latest research and standards development about BIM and its application in FM.

6D BIM is modelled in handing over procedure and usually intended for end users, owners and occupiers as a guide with all the necessary information which is given dynamically. One of the most important benefits of 6D BIM is an easy access to the facility element databases from which information about producer, type and model of equipment, and technical specifications can be accessed at any time. However, it usually does not provide information on the costs of maintenance and service intervals, as the rules of the profession demand. The article took advantage of 6D BIM model and used it for calculation of maintenance costs and their distribution in a time scale of 60 years. In this way, the facility manager manages information and supplements easily, while receiving information material in the traditional FM, such as the as-built drawings, instructions for operation and maintenance, certificates of completion and other technical documentation is of static importance.

On the other hand, regular implementation of the maintenance services is related to the applicable legislation. In Slovenia, the Construction Act (2004) defines the term facility maintenance from the technical aspect, representing execution of works whereby the object is maintained in good condition, and enables its use. Next, it defines the term regular maintenance, representing investment maintenance works, repairs, construction, installation and finishing works and improvements following the progress of technology. These works should not interfere in the structure of the building or change its intended use. The Article 6 (Construction Act, 2004) does not require obtaining a building permit for this works. From business perspective, Housing Act (2003) provides conditions for building maintenance whereas Rules on management of multiple dwellings (2009) 
specify functions of building management and powers of building manager. Further, in Rules on standards for the maintenance of apartment buildings and apartments (2004), the Annex 1 provides maintenance standards for 323 building elements with its and maintenance mode. In Slovenia, maintenance services are regulated only for multiresidential buildings, whereas legislative acts are applied mutatis mutandis for nonresidential buildings. Other countries have standards such as ISO 16739:2013 (covering industry foundation classes (IFCs); PAS 1192:1-5, (covering data format specification) and ISO 29481-1:2016 (covering BIM information manual), where the BIM and FM were developed. Thus, the Construction Operations Building Information Exchange (COBie) standard was elaborated (published in 2007 in the US and later adopted as British Standard in 2014) (Pärn et al., 2017), while Uniclass or Uniclass2 classification was developed within National Building Specification for the UK. In Slovenia, such a standard has not been implemented; therefore, the abovementioned legislative acts are applied.

This paper initially presents a general description of the business-storage facility in Slovenia. The core of the article exposes the detailed description of step-by-step procedure for planning of maintenance cost by using BIM approach for the FM (BIM4FM Group, 2017) on practical example. Thus, a 3D BIM model was designed to allow the preparation of an Element list for all elements that should be operated and maintained. Next, the service intervals and lifetime were determined for each element, followed by cost analysis. Based on the relevant data, planning of maintenance cost was developed in a unique way; cost calculation was created in Vico Office (VO) programme as linked data to 3D BIM model and the real cost plan was given in Excel tabular form because it allowed more explicit visual overview of planned maintenance.

\section{DESCRIPTION OF FACILITY}

\subsection{Location and Functional Design}

The business-storage facility is located in Hoče, Bohova 73, 2311 Hoče, Slovenia and is owned by the company Halder d.o.o. The building is functionally divided into the store with warehouse and the office space. The form of the building is an elongated rectangle with a roof above the entrance and above delivery space. The external dimensions are $36.5 \mathrm{~m}$ by $16.5 \mathrm{~m}$, the total gross area is $801.2 \mathrm{~m} 2$ and net surface is $715.3 \mathrm{~m} 2$. The business section (the store and the offices) has two floors, while the warehouse has a single storey and is double height (Arhilab, 2015). Figure 1 presents view on western façade and floor plan of the facility (Vincek, 2016).

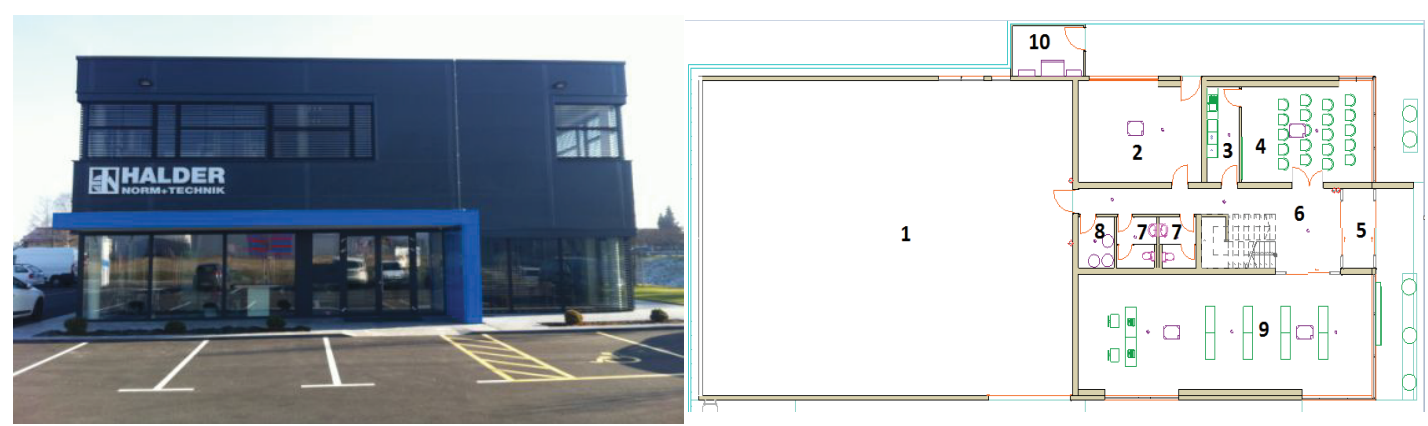

Figure 1: Western façade with the main entrance and floor plan of the facility 
Warehouse area (1), a workshop (2), a tea kitchen (3), a lecture room (4), a vestibule (5), a hallway (6), toilets (7), a boiler room (8), an exhibition room (9) and an outdoor space for cooling and heating devices (10) are on the ground floor. Different types of offices, an archive, a room for servers, toilets, and a room for cleaners are on the first floor.

\subsection{Technical Characteristics}

\subsubsection{Constructional Design}

The foundation of a business section is made with a reinforced concrete foundation plate. The load-bearing structure is a brick wall in thickness of $30 \mathrm{~cm}$. The foundation of a warehouse includes footings jointed by reinforced concrete beams. Load-bearing structure consists of reinforced concrete prefabricated elements which are longitudinally connected with steel sections/profiles. Reinforced concrete slab is used for mezzanine structure. The slope of the flat roof is $3^{\circ}$, implemented by trapezoidal metal sheet and system of hydro and thermal insulation according to DIN 18234. Façade panels with intermediate glazing cover the façade. Façade panels are fixed on the mounting steel substructure.

\subsubsection{Carpentry}

Aluminium windows with external blinds (Uf $=1,3 \mathrm{~W} / \mathrm{Km}^{2}, \mathrm{Ug}=1,0 \mathrm{~W} / \mathrm{Km}^{2}$ ) are mounted on the façade. Interior doors are made of metal doorframes and door panels are from solid wood or glazed. The main entrance and exit into exhibition area has double sliding glass doors monitored by sensor. The warehouse is equipped by an industrial sectional roll-up door whereas in the northern part of the building is a high delivery door.

\subsubsection{Internal Surface Treatment}

The final treatment of the ground in the warehouse includes surface-hardened reinforced concrete plate. Final coverings in business section were carried out by means of large format tiles and carpeting in offices. Ceramics is laid on the floor of toilets; walls and ceilings of the business section are lined with plasterboard panels. Sensors for fire protection, lighting and ventilation equipment are built-in in the raster suspended ceilings.

\subsubsection{Electrical Installations and Electrical Equipment}

Connection nominal power of the object is $\mathrm{Pn}=32,9 \mathrm{~kW}, \mathrm{In}=50 \mathrm{~A}$. The size of the fuse is $1 \times 3 \times 50$ A. Horizontal distribution pipes for electrical installations are carried on cable shelves, and a vertical pipe is placed in a protective tube in the walls. General and safety lighting is installed in the building. Telecommunication links are routed into the building through the telecommunications closet which is located in the room for the server.

\subsubsection{Active Technical Systems, Waterworks and Sewerage}

Heating of business section is provided by the heat pump air/water and the floor heating system. Heating of the warehouse is supplied by the heat pump air/air, which serves for office cooling in the summer. The external units of heat pumps and air conditioning are installed in the outdoor space on the south side of the facility.

Forced ventilation of business section includes two heat recovery units, an integrated filter and an air inlet and outlet fan. The transfer of outside (fresh) air and exhaust air is 
conducted through channels. Toilets have an intake ventilation valves and discharge pipe ventilators.

The facility is connected to the existing water supply network. It has an indoor fire hydrants and distribution pipes for hot water. Domestic hot water is supplied centrally by a combination water heater $(\mathrm{V}=100 \mathrm{l}$; heated with a heat pump or electricity). The facility is connected to the existing sewer system. A horizontal distribution pipe is made with polypropylene tube.

\section{ImPlementation of BIM to MaInTENANCE Cost Planning}

The following part introduces a detailed description of a step-by-step procedure for planning of maintenance cost by using BIM approach for the FM in unique way. The procedure begins with the collection of information about all facility elements and preparation of Element List for maintenance. After that, lifetime and service measures for each element are determined. Afterwards, the cost analysis is performed, which includes maintenance cost estimation model by using BIM approach and applying VO (with linked data to 3D BIM model elements). The final step displays created cost plan in tabular form as the timing of costs.

\subsection{Element List for Maintenance}

The first step to the creation of maintenance cost plan is to prepare an inventory and take-off quantities of all structural and non-structural elements requiring maintenance. In addition, also inventory of all installed equipment and installation must be prepared. The discussed facility input requires data obtained from as-built drawings and other technical documentation, which contains instructions for operation and maintenance, certificates of completion, Evidence on Reliability of the performed works, etc.

By collecting necessary information, the so-called Element list for maintenance is prepared in tabular form. The table is divided in several groups of works, namely construction and finishing works, installations, and external layout.

\subsection{Determination of the Lifetime and Service Measures}

The next step is determining lifetime and service measures for each maintenance element. We predicted lifetime of 60 years for business-storage facility. Relevant information for the individual elements is mostly taken from Rules on standards for the maintenance of apartment buildings and apartments (2004). The rule in Annex 1 provides maintenance standards for 323 building elements and in Annex 2 standards for 70 elements for equipment and maintenance of building lot. For each element the maintenance standards are defined and include: (I.) number, (II.) code in relation to group of works, (III.) description of an element, (IV.) normal lifetime, (V.) factor of theoretical replacement after 60 years, (VI.) factor for small repairs according to a new value, and (VII.) mode of maintenance works.

The service measures for elements defined in the Rule (2004) are recorded in the section VII and cover a variety of activities such as regular cleaning, regular servicing, regular review, repair of element, control of parts of the element, replacement of worn or damaged parts, painting, etc.

Data about estimated lifetime and modes of maintenance for elements not included in the Rule (2004) base on interviews with manufacturers or service providers or on data from COBie/Uniclass classification. The prices for servicing and implementation of regular maintenance work were acquired on the market. 
The maintenance modes for asphalt parking areas, as a part of the external layout, and for active fire protection, as part of electricity, are described more specifically. Modes for both elements are defined in the Annex 2 of the Rule (2004). For asphalt parking area Annex stipulates the 20-year lifetime span. Modes of maintaining are determined as a) regular maintenance and b) implementation of investment maintenance works two times in the intended lifetime. Regular maintenance is provided by a building caretaker and a qualified service technician with servicing equipment and includes surface cleaning on average 2 times a month, visual inspection, regular maintenance such as recovery of road markings every 5 years, and necessary repair of damage. Investment maintenance works are related to 60 years' period during which we anticipate 2 times replacement of surface layer. As defined in Rule (2004) we summarized the percentage of the value of small repairs in the amount of $15 \%$ from the initial value.

For active fire protection Annex 2 stipulates the 10-year lifetime span. Modes of maintaining are determined as a) regular cleaning and periodic reviews, and b) implementation of investment maintenance works five times in the intended lifetime. Regular cleaning is provided by a building caretaker, while periodic reviews by a qualified service technician. Investment maintenance works are related to 60 years' period during which we anticipate 5 times replacement of fire protection equipment system. As defined in Rule (2004) we summarized the percentage of the value of small repairs in the amount of $10 \%$ from the initial value.

\subsection{Cost Analysis}

The basis for estimating the maintenance costs are maintenance mode for all building elements, which must be maintained in the building lifetime. Cost estimation was performed by using VO. Data exchange from 3D Modeling Software, in our case ArchiCAD, to VO was carried out through the options "Publish to Vico" (Add-on in ArchiCAD). For each element we provided the unit price and multiplied it by the number of servicing intervals, replacements etc. throughout the entire lifetime of the building. In this way we estimated the annual costs and the total maintenance cost.

Estimation of the maintenance costs was discussed in two parts i) maintenance and replacement of individual elements in the building lifetime (characterized for construction and finishing works), and ii) servicing of installations and equipment (costs of regular servicing). For elements with lifetime 60 years or more, only the costs for maintaining were included in the calculation. In addition, the replacement costs were included for other elements.

To estimate the total maintenance costs of the facility, we considered two approaches: a) cost estimation for the construction of building elements and b) cost estimation for servicing elements.

\subsubsection{Cost Estimation for the Construction of Building Elements}

Input for estimation of maintenance and replacement costs for individual building element (e.g. concrete, masonry, ceramic works) are the amount of its construction costs. Construction costs were calculated by using the norms (Chamber of Craft and Small Business of Slovenia, 2015; Građevinska knjiga 2004) and the market prices of materials and labour. Cost estimation was performed by VO, representing a Project Management Software designed for the BIM approach and joining 3D, 4D and 5D BIM. VO was chosen because it can easily and very accurately determine the quantities required for cost analysis. 
First we designed a detailed 3D BIM model of the business-storage facility. The model was created in the ArchiCAD program, and afterwards imported into the VO. Other programs can also be used for 3D BIM model, e.g. Revit, Allplan, or other Modeling Software. 5D BIM model for all structural and non-structural elements was subsequently developed in module Cost Planner. In this module we determined the individual building elements and divided them in three types of works: the construction and finishing works, installations and external layout. In this way, we created an Element list (see Figure 2).

\begin{tabular}{|c|c|c|c|c|c|c|c|c|c|}
\hline Code & Description & Source $Q$. & Consumpti. & Consump.. & Waste & Qty & UOM & Unit Cost & Base Cost \\
\hline 01 & Halder_18_4 & 1,00 & 1,000 & 1,000 & 1,000 & 1,00 & & $403.255,15$ & $\triangle 403.255,15$ \\
\hline$=1.0 .0 .0$ & CONSTRUCTION AND FINISHING WORKS & 1,00 & 1,000 & 1,000 & 1,000 & 1,00 & kpl & $267.680,51$ & A $267.680,51$ \\
\hline+1.10 .0 .0 & PAINTS AND COATINGS & 1,00 & 1,000 & 1,000 & 1,000 & 1,00 & $\mathrm{~m} 2$ & $4.913,30$ & $A \quad 4.913,30$ \\
\hline +1.9.0.0. & LOCKSMITH WORKS & 1,00 & 1,000 & 1,000 & 1,000 & 1,00 & kos & $1.600,00$ & $\triangle \quad 1.600,00$ \\
\hline + 1.8.0.0. & FLOORS - PAVEMENTS & 1,00 & 1,000 & 1,000 & 1,000 & 1,00 & $\mathrm{~m} 2$ & $18.123,23$ & $A \quad 18.123,23$ \\
\hline+1.7 .0 .0 & FIIISHING OF WALLS AND CEILINGS & 1,00 & 1,000 & 1,000 & 1,000 & 1,00 & $\mathrm{~m} 2$ & $34.545,37$ & A $34.545,37$ \\
\hline+ +1.6.0.0. & CARPENTRY & 86,00 & 1,000 & 1,000 & 1,000 & 86,00 & kos & 846,28 & $\Delta \mathbf{7 2 . 7 8 0 , 5 0}$ \\
\hline +1.5.0.0. & STAIRCASES & 1,00 & 1,000 & 1,000 & 1,000 & 1,00 & kpl & $8.523,68$ & $\Delta \quad 8.523,68$ \\
\hline +1.4.0.0. & FAÇADE & 541,25 & 1,000 & 1,000 & 1,000 & 541,25 & $\mathrm{~m} 2$ & 51,47 & A $27.859,18$ \\
\hline +1.3.0.0. & ROOF & 534,37 & 1,000 & 1,000 & 1,000 & 534,37 & m2 & 98,64 & $\Delta \quad 52.711,09$ \\
\hline +1.2.0.0. & CONSTRUCTION OF BUILDINGS & 1,00 & 1,000 & 1,000 & 1,000 & 1,00 & m3 & $41.123,50$ & $\triangle 41.123,50$ \\
\hline +1.1.0.0 & FOUNDATION & 53,50 & 1,000 & 1,000 & 1,000 & $53,50 \mathrm{r}$ & m3 & 102,82 & $\triangle \quad 5.500,66$ \\
\hline-2.0 .0 .0 & INSTALLATIONS & 1,00 & 1,000 & 1,000 & 1,000 & 1,00 & kpl & $121.939,67$ & A $121.939,67$ \\
\hline+2.9 .0 .0 & SMALL/FINE GRADE EQUIPMENT & 1,00 & 1,000 & 1,000 & 1,000 & 1,00 & kos & 525,00 & 525,00 \\
\hline+2.7 .0 .0 & REMOVAL DEVICE & 1,00 & 1,000 & 1,000 & 1,000 & 1,00 & kos & 300,00 & $\triangle \quad 300,00$ \\
\hline+2.6 .0 .0 & VENTILATION & 1,00 & 1,000 & 1,000 & 1,000 & 1,00 & kpl & $15.175,32$ & $\Delta \quad 15.175,32$ \\
\hline+2.5 .0 .0 & HEATING AND COOLING & 1,00 & 1,000 & 1,000 & 1,000 & 1,00 & kpl & 48.163,94 & A $48.163,94$ \\
\hline +2.3.0.0. & ELECTRICITY & 1,00 & 1,000 & 1,000 & 1,000 & 1,00 & kpl & $45.512,93$ & A $45.512,93$ \\
\hline +2.2.0.0. & PLUMBING AND SANITARY EQUIPMENT & 1,00 & 1,000 & 1,000 & 1,000 & 1,00 & kpl & $5.861,48$ & $\triangle \quad 5.861,48$ \\
\hline+2.1 .0 .0 & SEWERAGE - INTERIOR & 1,00 & 1,000 & 1,000 & 1,000 & 1,00 & kpl & $6.401,00$ & $\begin{array}{l}\Delta \quad 6.401,00 \\
\end{array}$ \\
\hline-3.0 .0 .0 & MAINTENANCE OF EXTERNAL SURFACES & 1,00 & 1,000 & 1,000 & 1,000 & 1,00 & $\mathrm{~m} 2$ & $13.634,97$ & A $13.634,97$ \\
\hline+23.0 .0 & LAWN & 387,00 & 1,000 & 1,000 & 1,000 & 387,00 & $\mathrm{~m} 2$ & 1,52 & 588,24 \\
\hline+6.0 .0 & PARKING & 869,78 & 1,000 & 1,000 & 1,000 & 869,78 & $\mathrm{~m} 2$ & 15,00 & A $13.046,73$ \\
\hline
\end{tabular}

Figure 2: Elements list created in $\mathrm{VO}$

This was followed by the implementation of cost estimation: first, quantities (Source quantity) and norms (Consumption) of each resource are given; next, the final quantity (Quantity or Qty) with the appropriate unit of measure (UOM) and price per unit (Unit Cost) is determined; and finally, the total cost of each element is calculated in the Base Cost column. These costs were the basis for estimated costs for replacing and maintaining elements. Thus, costs of replacing are calculated according to the factor of theoretical replacement after 60 years while maintenance costs regard the factor for small repairs according to a new value.

Two examples of estimating the maintenance costs are presented here: for asphalt parking area and fire protection equipment. The lifetime for asphalt area is estimated on 20 years. As stated in chapter 3.2, two replacements are planned (in $20^{\text {th }}$ and $40^{\text {th }}$ years) which amounts to $€ 13046,73$. During 60 years period, $15 \%$ of initial value needs to be invested in regular maintenance. Costs are distributed evenly through the years of the building lifetime and amounts $€ 99,51$ per year. The lifetime for fire protection equipment is estimated on 10 years. The price of new equipment with an installation was obtained on the market and calculated to $€ 4957,53$. Costs for small repairs represents $10 \%$ from the initial value, where initial value includes the purchase value of the equipment and its five times replacement, which amounts in total $€ 29745$,20. These costs amount to $€ 50,41$ and are distributed evenly through the period of 60 years.

\subsubsection{Cost Estimation for Servicing Elements}

We considered regular servicing costs for built-in installations and equipment for estimation of these costs. Regular servicing intervals are mostly prescribed by legislation, e.g. for fire protection equipment with Fire Protection Act (2007). We acquired prices for the services in the market by authorized service. 
As an example, we present the costs of servicing installations and equipment for active fire protection. We anticipated annual regular servicing costs, amounting to $€ 400$, namely we considered four services per year at a price $€ 100$. In $1^{\text {st }}$ and every tenth year just three services are required. In period of 60 years in total 230 services are needed.

\subsection{Display of created cost plan by using BIM}

Based on the data obtained in previous steps, cost plan of maintenance work was modelled by using BIM approach for the FM to specify all costs for regular and investment maintenance in the intended lifetime of the facility. The plan was made in a unique way by using the VO (with connection to 3D BIM model) for cost calculations; and the MS Excel was employed for the presentation of the timing of the cumulative costs by years. In addition, the distribution of the cumulative costs considered service intervals and the interventions for the regular maintenance of the elements. Such a unique way is very suitable for use in practice, because MS Excel is widespread in practice, and end users or owner is qualified to use. In this way, the owner avoids purchasing of specialized software and training required for its use.

Tabular form was used for displaying created cost plan, since a display for the operating phase over 60 years was more transparent. It was made with the help of MS Excel. Figure 3 shows graphical presentation of the cost plan for execution of maintenance work in the first 20 years for electricity and external layout. The vertical axis represents the elements of the building and the horizontal axis time in years.

\begin{tabular}{|c|c|c|c|c|c|c|c|c|c|c|c|c|c|c|c|c|c|c|c|c|c|c|}
\hline & & & \multicolumn{20}{|c|}{ TIME AFTER CONSTRUCTION IN YEARS } \\
\hline \multicolumn{3}{|c|}{ Item/element number/description } & - & N & $m$ & + & n & 0 & $\wedge$ & $\infty$ & $\sigma$ & 으 & $=$ & $\cong$ & $\stackrel{m}{=}$ & $\Xi$ & 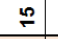 & $\because$ & $\bumpeq$ & $\stackrel{\infty}{-}$ & $\stackrel{9}{\longrightarrow}$ & กิ \\
\hline \multirow{4}{*}{ 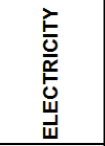 } & 46 & Electrical Installations & 199 & 199 & 199 & 199 & 199 & 199 & 199 & 199 & 199 & 199 & 199 & 199 & 199 & 199 & 199 & 199 & 199 & 199 & 199 & 199 \\
\hline & 47 & Connection to electricity grid & 3 & 3 & 3 & 3 & 3 & 3 & 3 & 3 & 3 & 3 & 3 & 3 & 3 & 3 & 3 & 3 & 3 & 3 & 3 & 3 \\
\hline & 48 & Lightning installation & 3 & 3 & 3 & 3 & 3 & 3 & 3 & 3 & 3 & 3 & 3 & 3 & 3 & 3 & 3 & 3 & 3 & 3 & 3 & 3 \\
\hline & 49 & Active fire protection & 350 & 450 & 450 & 450 & 450 & 450 & 450 & 450 & 450 & 5308 & 450 & 450 & 450 & 450 & 450 & 450 & 450 & 450 & 450 & 5308 \\
\hline ASPHALT & 64 & Renewal of the surface layer & 100 & 100 & 100 & 100 & 100 & 100 & 100 & 100 & 100 & 100 & 100 & 100 & 100 & 100 & 100 & 100 & 100 & 100 & 100 & 13047 \\
\hline ASPHALT & 65 & Road markings on the parking & & 268 & & 268 & & 268 & & 268 & & 268 & & 268 & & 268 & & 268 & & 268 & & 268 \\
\hline LAWN & 66 & Mowing grass and fertilizing & 588 & 588 & 588 & 588 & 588 & 588 & 588 & 588 & 588 & 588 & 588 & 588 & 588 & 588 & 588 & 588 & 588 & 588 & 588 & 588 \\
\hline
\end{tabular}

Figure 3: Section of the cost plan of maintenance work for the business-storage facility (Vincek, 2016)

After completion of cost plan for execution of maintenance work it was followed the estimation of the total maintenance costs for the whole building. Costs are on an annual basis attributed for each element classified in individual groups of works. (Vincek, 2016).

\section{CONCLUSION}

This paper presents procedure for planning of maintenance cost for the real businessstorage facility in Slovenia using BIM approach. Our case study provides information of costs for maintaining building for the user, i.e. Halder Company, in a unique and transparent manner. Initially, general principles of FM and BIM and features of facility maintenance in general and according to the current Slovenian legislation are addressed in the Introduction. Thereupon, basic description of business-storage facility is given in Section 2. Step-by-step procedure for planning of maintenance cost is introduced in Section 3. In addition, cost analysis, including maintenance cost estimation, is performed by using BIM approach and application of VO software and cost plan with the help of MS Excel. 
The paper could serve as a guide to the facility owners or end users in order to prepare a real cost plan for a whole period of building operation and in this way providing an insight into the relevant dynamic information about costs for execution of maintenance works. Further, the adequate planning of relevant activities and its costs enables the owner to avoid unforeseen situations and problems regarding the functioning of the facility which could arise as a result of improper maintenance.

The proposed use of BIM approach for FM is presented in a unique way due to the lack of a uniform methodology linking the scope of FM and BIM. Also, the compatibility of software for FM and BIM is at a low level. The accessible literature has not yet detected a large number of case studies and practical examples for this area which directs us to further research.

\section{REFERENCES}

Arhilab d. o. o. (2015). Business-storage facility in Hoče. Final project, Maribor, Slovenia. Becerik-Gerber, B., Jazizadeh, F., Li;, N., Calis, G. (2012). Application Areas and Data Requirements for BIM-Enabled Facilities Management. Journal of construction engineering and management, 138(3), pp. 431-442.

BIM Task Group, BIM4FM Group, Available at: http://www.bimtaskgroup.org/bim4fmgroup/, [Accessed 19 Apr. 2017].

BIMobject ${ }^{\circledR}$ Corporation, Nimbus-Compact, Ariston, Available at: https://bimobject.com/en/ariston/product/nimbus-compact, [Accessed 9 Apr. 2017].

Construction Act. Official Gazette of the Republic of Slovenia, No. 102/04, 126/07, 108/09, 20/11-Decis. CCS, 57/12, 110/13, 19/15.

Designing BuildingsWiki. BIM and facilities management. Available at: http://www.designingbuildings.co.uk/wiki/BIM_and_facilities_management, [Accessed 7 Dec. 2016].

Ding, L., Zhou, Y., Akinci, B. (2014). Building Information Modeling (BIM) application framework: The process of expanding from 3D to computable nD. Automation in Construction, 46, pp. 82-93.

Eastman, C., Teicholz, P., Sacks, R., and Liston, K. (2011). BIM Handbook: A Guide to Building Information Modeling for Owners, Managers, Designers, Engineers and Contractors, 2nd ed. John Wiley \& Sons, New Jersey.

Fire Protection Act. Official Gazette of the Republic of Slovenia, No 3/2007, 9/2011, $83 / 2012$.

Housing Act. Official Gazette of the Republic of Slovenia, No. 69/2003, 57/2008, 56/2011Decis. CCS, 87/2011.

McArthur, J.J. (2015). A building information management (BIM) framework and supporting case study for existing building operations, maintenance and sustainability. Procedia Engineering 118, pp. 1104 - 1111.

NIBS, (1998). Excellence in Facility Management. National Institute of Building Sciences, Facility Maintenance and Operations Committee, 5350-1. Defining High Performance Buildings for Operations and Maintenance.

Nicał, A.K., Wodyński, W. (2016). Enhancing Facility Management through BIM 6D. Procedia Engineering, 164, pp. 299 - 306.

Pärn, E.A., Edwards, D.J., Sing, M.C.P. (2017). The building information modelling trajectory in facilities management: A review. Automation in Construction, 75, pp. $45-55$. 
Pučko, Z., Šuman, N., Klanšek, U. (2014). Building information modeling based time and cost planning in construction projects. Organization, technology \& management in construction: An International Journal, 6(1), pp. 958-971.

Roper, K. O., Payant, R. P. (2014). The Facility Management Handbook, 4th ed. Amacom, New York.

Rules on management of multiple dwellings. Official Gazette of the Republic of Slovenia, No. 60/2009, 87/2011, 85/2013.

Rules on standards for the maintenance of apartment buildings and apartments. Official Gazette of the Republic of Slovenia, No. 20/2004, 18/2011.

Sabol, L. (2008). Challenges in Cost Estimating with Building Information Modeling, Design + Construction Strategies, Washington.

The norms and standards of work in the construction industry. (2004). Gradevinska knjiga, Beograd.

The norms for concrete and reinforced concrete work. (2005). Chamber of Craft and Small Business of Slovenia, Construction Section, Ljubljana.

Trimble Navigation, Ltd. Vico Office R5.2. Available at: http://support.vicosoftware.com/FlareFiles/Content/SupportLink/Downloads.htm [Accessed 9 Oct. 2016]

Vincek, D. (2016). 6D building information model of Halder d. o. o. enterprise in Hoče. Master thesis, Faculty of Civil Engineering, Transportation Engineering and Architecture, University of Maribor, Maribor. 